\title{
ANNOTATIONS
}

\section{A Much-needed Reform}

Among the many duties of the State the examination of the physical fitness of the candidates for the various branches of its service is not least important. Many have defects of vision, and the different departments of the Government have drawn up regulations as to the standards of vision which the candidates are required to possess in order to qualify for particular posts and occupations. Thus vision testing in some form or other is one of the functions of officials of such widely diverse departments as the War Office, the Admiralty, the Post Office, the Board of Trade (Mercantile Marine Department), as well as other sections of the Civil Service. The preliminary testing is usually of a simple character and does not require very complicated apparatus, yet it is only fair to the candidates that the conditions should be so arranged that the results are strictly comparable to the standards. As a matter of fact this is seldom the case. Visual acuity, for instance, is estimated in terms of Snellen's test types. Every ophthalmic surgeon knows that the estimate varies very considerably according to the illumination of the types; yet no official regulations of any department state the illumination of the standard, and in actual practice the illumination may vary from bright diffuse daylight to dull artificial light, i.e., many hundred candle-powers. This is but one of many criticisms which might be made. These tests use the language of science : many of them are utterly unscientific, and in their practical application no pretension is made to scientific accuracy. It is no exaggeration to say that there are many regulations relating to eyesight now in force which arouse the caustic humour, and often the moral indignation, of ophthalmologists. All these regulations require revision by competent experts, those bêtes noires of officialdom. There should be a standing committee of the best ophthalmologists in the country to deal with these and the many other problems relating to eyesight. The committee should be appointed by the Government after consultation with the Ophthalmological Society and the Ophthalmological Section of the Royal Society of Medicine. It should not be attached to any special Government department, but it should be made compulsory for all departments to refer such matters to the consideration of the committee for report.

Owing to the inadequacy of the existing tests, and other causes, it has been found necessary in many departments to allow an appeal from the decisions of the ordinary examiners. In several cases the candidates are required to pay a substantial fee to enable 
them to avail themselves of this concession. The conditions under which these appeal examinations are carried out are often lamentable. Rooms quite unfitted for the purpose are used, the test types are badly illuminated, and ophthalmoscopic examination and retinoscopy are done under the most unfavourable conditions. When one realizes that the candidate's future career may depend upon the result of the examination, and that in many cases a fee has been exacted as a token of good faith-surely as much on the part of the State as on that of the candidate-it cannot be denied that some reform is urgently demanded. Under existing circumstances each department makes its own arrangements, and in at any rate one department, it avails itself of the private apparatus belonging to one of the examiners. In this case certainly no fault is to be found with the conditions, but the method is not one which it is desirable that the State should sanction. The obvious way out of the very trivial difficulty is to have one central, properly equipped examination hall, provided ${ }^{-}$with dark rooms, laboratories, $\& \mathrm{c}$. , for the use of all the departments.

\section{Ophthalmology in Italy.}

In the September number of this journal we published some account of the beneficent work that is being accomplished in America by the National Committee for the Prevention of Blindness, a Committee largely composed of clear-headed business men who are able to see far enough ahead to recognize the commercial value of such work to the State. To judge from a contribution by Dr. Alajmo, of Girgenti, in the May-June number of the Annali di Ottalmologia e Clinica Oculistica of this year, some similar patriotic action is badly needed in Italy. The point that has roused him to a height of wrath that may be described as dithyrambic-he quotes Ovid and other classical authorities-is the recommendation of a recent Royal Commission for the reform of University study to abolish the study of ophthalmology. We can only hope that there must be some misunderstanding, but, should the facts be as stated, we do not think that Alajmo transgresses the limits of fair controversy in referring to the members of that Commission as "rimbambiti," childish idiots. He refers to the noble traditions of Italian ophthalmology, instancing men like Barth, the founder of the Vienna School. He complains bitterly that the modern Italian seems to regard ophthalmology as an almost negligible branch of medicine. His indictment is a very heavy one. Thus, though the loss of a finger in war carries an indemnity, there is no compensation for the loss of an eye. Trachoma is rife and yet there is no compulsory notification or treatment for that terrible scourge. In the question of this complaint our own hands are not too clean, as any worker in the East End of London can testify. Again, he 
complains that the sale of glasses is largely in the hands of ignorant quacks. A recent and important work entitled "Contributions to Social Hygiene and Pathology," by Professor Devoto, of the Milan Clinic, for the study of these questions contains no mention of ocular maladies. The result of public neglect of the eye is seen in the almost cynical way in which loss of an eye is regarded by the poorer classes; thus many men destroy an eye with the object of avoiding military service. Legislative measures for the protection of workers against such diseases as ankylostomiasis and malaria are enforced, but there are no measures taken to protect the eyes of the reapers from a common form of keratitis which claims many victims every year.

We fear that the difficulty of inducing politicians to look ahead will always militate against the enforcement of necessary but unpopular measures like the compulsory notification of trachoma. Even from the lowest commercial point of view the loss caused by preventible blindness - and how much blindness is preventible is well known to every ophthalmic surgeon-should cause governments to take strong action in such an important matter.

Professor Cirincione adds a note on the great improvement that has taken place in the ophthalmic arrangements for the Army. As he points out, Italy, like the rest of the Allies, was quite unprepared for war on a large scale, and had to improvise a service. Naturally mistakes occurred at the beginning which are now being put right. $\mathrm{He}$ is able to note with great pleasure the decision of the military authorities to use trachomatous recruits, first collecting them into special centres for treatment. He hopes that in this way trachoma may be brought under control as has been done in the last ten years in the Austrian Army. The recruits from Silesia and the lower Danube regions formerly gave 26 per cent. of trachomatous subjects, which has now been reduced to less than $1 \frac{1}{2}$ per cent. In addition to the beneficial results of treatment, the numerous cases in which trachoma has been deliberately inoculated in order to avoid military service will disappear. Cirincione goes as far as to say that the war may prove a blessing in disguise if it results in getting control over the dreaded scourge of trachoma and removing Italy from her present sad position as the leading European country in the statistics of contagious conjunctival disease. 